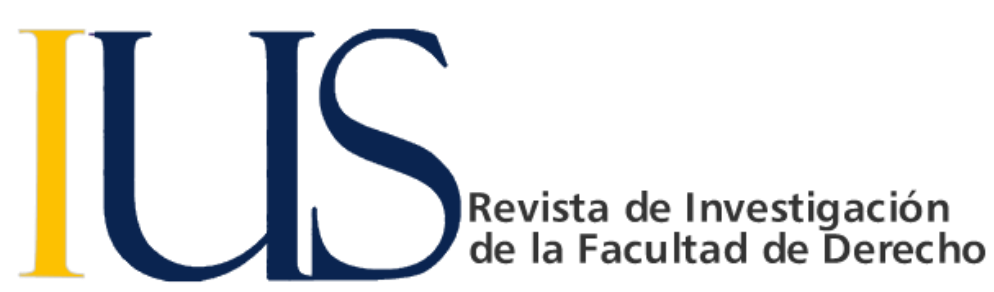

\title{
Perú - Alemania. ¿Cómo operaba la diplomacia durante el III Reich? (1935 - 1937)
}

\author{
Jorge Luis Vallejo ${ }^{1}$
}

\section{INFORMACIÓN DEL ARTÍCULO}

\section{Historia del artículo:}

Recibido el 23 de mayo de 2011

Aceptado el 15 de junio de 2011

\section{Palabras claves:}

Ciencia política

Relaciones internacionales

Diplomacia

III Reich

Nazismo

\section{RESUMEN}

El presente artículo apunta a contribuir con los estudios de Ciencia Política bajo la línea de las Relaciones Internacionales desde la historia política de la actuación de nuestra Cancillería, explorando las relaciones diplomáticas del Perú con el III Reich Alemán, por ello esta investigación se centra en torno a los legajos diplomáticos guardados en los repositorios del Ministerio de Relaciones Exteriores peruano, se ha sistematizado la documentación referente a los años de 1935, 1936 y 1937, tiempos de la ya plena instalación del régimen nazi en Alemania, previos a la conflagración mundial. Se muestran así diversos extractos de documentos que salen a luz luego de varias décadas de postergación.

Queda aún mucha más valiosa información por ser tratada, este trabajo se divide en 4 acápites a saber: En primer lugar se observan las quejas encontradas, formuladas por ciudadanos peruanos ante nuestra Legación en Alemania. Son 2 las reclamaciones halladas: el caso Hochkoeppler y el caso Ebentreich. Como segundo acápite tenemos las incidencias sobre la participación de la delegación de football peruana en las Olimpiadas de Berlín. El tercer apartado aborda las relaciones de colaboración y amistad entre Alemania y Perú, que también las hubo con diversas manifestaciones durante el período observado. Ya en el cuarto punto se analizan otras informaciones diversas brindadas por la Legación peruana y que he considerado de relevancia para enfocar las relaciones con el régimen alemán.

Peru - Germany. How did diplomacy operate during the III Reich? (1935-1937)

\section{Introducción}

Tal y como ya se ha referido, se observa en la documentación revisada 2 casos de afectación a peruanos. Es interesante ampliar el desarrollo de dichas quejas en tanto parte de la función diplomática consiste en atender este tipo de situaciones en pro del bienestar de los connacionales.

\section{EL CASO HOCHKOEPPLER}

Es en el año 1935 en que Ernesto Hochkoeppler presenta su reclamación ante las autoridades peruanas en Alemania por haber sido prohibido de ejercer la medicina en dicho país. Este proceso durará hasta 1938 con continuas comunicaciones entre el Ministerio de

\footnotetext{
${ }^{1}$ Politólogo por la Pontificia Universidad Católica del Perú. Profesor de Ciencia Política de la Facultad de Derecho de la Universidad Católica Santo Toribio de Mogrovejo - Chiclayo, Perú.
} 
Relaciones Exteriores en Lima y la representación en Berlín.

"La Legación del Perú tiene el honor de poner en conocimiento del Ministerio de Relaciones Exteriores lo siguiente: El Dr. en medicina Ernesto Hochkoeppler de nacionalidad peruana, con domicilio en Stuttgart, recibió a principios del presente mes una comunicación de la Asociación de Médicos de Stuttgart en el sentido de que la Asociación Médica, en vista de las nuevas leyes, se veía obligada a examinar si el señor Dr. Hochkoeppler, en su calidad de extranjero podía seguir ejerciendo la profesión de médico en la "Caja Local de Enfermos de Stuttgart'2".

En la documentación se nota la preocupación de los diplomáticos peruanos ante esta situación, es así como el Cónsul del Perú en Stuttgart, señor Carlos Sutorius, se reúne con el Presidente de la Asociación Médica de dicha localidad, Dr. Feldmann, éste último dice que el caso será sometido a un "debate minucioso $3 "$.

La resolución fue negativa anulándosele definitivamente a Hochkoeppler el permiso para ejercer la profesión de médico en la "Caja Local de Enfermos".

No se trataba de un extraño para Alemania pues Hochkoeppler ya antes se había alistado en el ejército voluntariamente y por causa de una herida en la rodilla se le dio de baja, ante lo cual él - consciente de su situación - decide descartar cualquier objeción y dimite a todo derecho.

En el año 1922 recibió el título de médico en Alemania y tal parece, según indican desde la Legación peruana, que en la Ley de oficios y profesiones del Reich no existiría ningún tipo de incompatibilidad para el trabajo de Hochkoeppler ${ }^{4}$.

Este peruano alega que perder su permiso para trabajar en las Cajas Locales de Enfermos sería su ruina, finalmente está dispuesto a volver al Perú si se le deja retirar su dinero de Alemania, dicho dinero había sido bloqueado.

Días después la Asociación Médica de Stuttgart comunica que definitivamente Hochkoeppler ha quedado impedido de ejercer la medicina, ante esto la Legación peruana es enfática en señalar:

"Se trata, pues, en el presente caso de una cancelación parcial de los derechos de un ciudadano peruano ${ }^{5 \prime \prime}$.
"La Legación del Perú se ve obligada a apoyar al Dr. Hochkoeppler [...] y ruega al Ministerio de Relaciones Exteriores se sirva gestionar que a más tardar hasta el 10 de diciembre se ponga a disposición del Dr. Hochkoeppler las divisas, puesto que él se ve obligado a abandonar Alemania en dicha fecha ${ }^{6 \prime \prime}$.

Un año después, en 1936, se vuelve a tener noticias sobre este caso. El Ministro Plenipotenciario del Perú en Alemania H.E. Gildemeister informa de una reunión sostenida con el Ministro Plenipotenciario Dr. Poensgen, Jefe de la Sección de "América" del Ministerio de Relaciones Exteriores Alemán, con miras a "tratar una solución definitiva para la reclamación de nuestro compatriota Dr. Hochkoeppler" 7 . Se busca así asentar en "términos firmes" el reclamo por la indemnización a favor del referido médico.

El Dr. Poensgen señala que el Encargado de Negocios de Alemania en Lima informó a su Ministerio que el Dr. Hochkoeppler había comunicado que:

"si el Gobierno Alemán le permitía nuevamente ejercer su profesión de médico en Alemania, concediéndole además una colocación en una clínica del país, él estaba pronto a regresar inmediatamente, considerándose indemnizado en todos los daños que había sufrido y que eran motivo de la reclamación que esta Legación había planteado ante el Gobierno Alemán"8.

En tal sentido debido a que Hochkoeppler ya se encontraba negociando una salida a su reclamación de modo directo con la Legación alemana en Lima, la Legación peruana en Berlín consideró que su intervención "resulta ya innecesaria" ${ }^{9}$.

Con el transcurrir del tiempo al parecer se va llegando a una solución en este caso, puntualmente en lo que respecta a la recuperación de los fondos bloqueados. Al respecto se tiene una nueva comunicación del Ministerio de Relaciones Exteriores del Perú a su Legación en Alemania:

"El Ministerio de Relaciones Exteriores ve con satisfacción que se haya podido acceder a la solicitud de la Legación relativa a la inversión de los fondos bloqueados del doctor Hochkoeppler. Respecto de la transferencia del seguro de vida del doctor Hochkoeppler al fondo suizo de la Compañía Suiza de Seguros y Rentas, se ruega encarecidamente ponerse

\footnotetext{
${ }^{6}$ Oficio del 4 de diciembre de 1935.

${ }^{7}$ Oficio del 14 de diciembre de 1936.

8 Ibídem.

9 lbídem.
}

\footnotetext{
2 Oficio del 31 de agosto de 1935.

3 Ibídem.

${ }^{4}$ lbídem.

5 Oficio del 29 de octubre de 1935.
} 
de aquí en adelante en contacto directo con la oficina de dicha Compañía en Muenchen ${ }^{10 "}$.

Posteriormente, la Legación del Perú solicitaría a la Oficina Imperial de Economía de Divisas de Alemania que los fondos bloqueados de Hochkoeppler sean destinados a cubrir los gastos por el viaje de la esposa de dicho compatriota, la cual se dirige a Europa debido a la enfermedad de su hijo menor.

Luego de tantas negociaciones, se logra poner fin al problema en 1938, la diplomacia peruana había llegado a lanzar en el transcurrir de las negociaciones un "incentivo negativo", vía "amenaza" al gobierno de Alemania:

"Entre las gestiones que el Gobierno peruano desarrolló para obtener una reparación, se encontró la formulación de una protesta que llegó al extremo de advertir al Gobierno alemán que se adoptarían similares medidas contra los médicos alemanes radicados en el Perú de no repararse el hecho ${ }^{11 "}$.

\section{EL CASO EBENTREICH.}

Este es el segundo caso hallado en la documentación de la Cancillería sobre hostigamiento a peruanos en la Alemania nazi. El peruano Alfredo Ebentreich se ve obligado a abandonar Alemania sin que se halle una solución para su caso:

"El señor Alfredo Ebentreich se ha visto obligado a retirarse de la Casa Peruana a causa de las hostilidades continuas de parte de las autoridades locales de Munich, y se ha dirigido hace algunos días al Perú. Según se me ha informado, se habría amenazado aun al señor Ebentreich con detención ${ }^{12 "}$.

Es extraño que no se puedan remediar estas actitudes hostiles contra el peruano Ebentreich, actitudes llevadas a cabo por un miembro de la Policía Secreta nazi de quien se dice que no atiende los llamados de atención del Gobierno ni del Partido, cabría preguntarse si fue del todo cierto que se efectuaron estos llamados de atención o si de haberse efectuado se hicieron con la presión debida:

"La persona encargada de las cuentas de la Casa Peruana por parte de las autoridades alemanas es el Dr. Baversfeld, a la vez miembro de la Policía Secreta del Estado, contra cuyas arbitrariedades nada pudieron hacer ni el Gobierno, ni las autoridades superiores del

\footnotetext{
10 Oficio del 13 de setiembre de 1937.

${ }^{11}$ Novak, Fabián. Las relaciones entre el Perú y Alemania (1828 2003). Lima: Fondo Editorial de la Pontificia

Universidad Católica del Perú, 2004, p.115. Tomado de: Wagner, Alberto. Historia diplomática del Perú 1900-1945. Lima: Fondo Editorial del Ministerio de Relaciones Exteriores del Perú, 1997, p.285. Ministerio de Relaciones Exteriores del Perú. Memoria del 23 de octubre de 1936 al 29 de octubre de 1937. Lima: 1939, pp.10-12.
}

Partido. Esto puede explicarse si se tiene en cuenta que la Policía Secreta del Estado y sus funcionarios son autónomos en todos sus pasos, y sólo responsables de sus actos ante el Jefe superior ${ }^{13 \prime}$.

La responsabilidad de Baversfeld únicamente ante el Jefe Superior de la Policía Secreta y el hecho de que sus malas actitudes hacia los compatriotas de la Casa Peruana no se remediasen, sólo puede significar que el alto mando de la Geheime Staatspolizei (Gestapo) no buscó dar solución a tales incidentes.

"Después de esta experiencia, veo que la Casa Peruana no va a poder sostenerse a la larga. Gran parte de los pensionistas fundadores de la Casa Peruana se han retirado de ella y han sido reemplazados por otros menos. Además, según información del señor Ebentreich, se está formando entre los más jóvenes un grupo con tendencias apristas muy marcadas.

Este hecho y el retiro del señor Ebentreich no ofrecen para el futuro seguridad alguna de que los estudiantes alojados en la Casa Peruana se dediquen al estudio serio $^{14 "}$.

Es importante notar la mención a la presencia de los jóvenes apristas como un punto negativo para la Casa Peruana. Este referente negativo sin duda alguna se debe a la proscripción (heredada del gobierno de Luis Sánchez Cerro) del Partido Aprista Peruano durante el régimen del General Benavides.

Tal vez por ello poco se hizo por pelear este caso ante el Gobierno del Reich (como sí se hizo con el problema del doctor Hochkoeppler).

El consejo de la Legación peruana fue distribuir a los jóvenes alojados en la Casa Peruana en otras universidades alemanas o fuera de este país ${ }^{15}$.

\section{3. “EL TRIUNFO ROBADO”. PERÚ Y LAS OLIMPIADAS DE BERLÍN 1936.}

Ofrezco un acápite especial para atender el "incidente del equipo de football" 16 en tanto este suceso, la anulación del partido en el que la delegación de football peruana venció al equipo austriaco, conllevó a gestiones diplomáticas e incluso a una cierta agitación social. No pocas veces hemos escuchado hablar de este incidente como una "leyenda" deportiva, aquí van los fundamentos del caso, hasta ahora poco conocidos, la documentación diplomática ${ }^{17}$ enviada por la

\footnotetext{
12 Oficio del 3 de marzo de 1936.

13 Ibídem.

${ }^{14}$ Ibídem.

15 Ibídem.

${ }^{16}$ Oficio del 20 de agosto de 1936.

17 Ibídem.
} 
Legación peruana al Ministerio de Relaciones Exteriores en Lima es bastante detallada y muestra toda la secuencia del incidente.

El 6 de agosto de 1936 el equipo peruano jugó contra el "team" de Finlandia en el estadio de Hertha, triunfo peruano por 7 a 3 "goals". La prensa alemana se mostró favorable con este resultado y el desempeño del equipo peruano.

El sábado 8 de agosto en ese mismo estadio tocó jugar contra los austriacos, el partido terminó 2 a 2, pero en los tiempos suplementarios el equipo peruano logró imponerse por un 4 a 2. El vicepresidente de la FIFA felicita al señor Martínez, presidente de la delegación peruana, y dice ver al equipo como "seguro finalista". En este encuentro la prensa también se mostró a favor. Ya para la tarde del martes 11 tocaba jugar las semifinales ante Polonia en el estadio Olímpico.

En la mañana del lunes 10, Martínez es notificado por la FIFA de un reclamo contra el triunfo peruano interpuesto por la delegación austriaca pidiendo la anulación del partido. Son 3 las razones que dan para ello:

a) Dicen que el público invadió el campo de juego y que se cometió agresión contra un jugador austriaco.

b) Acusan que el campo de juego no prestaba condiciones de seguridad ni las medidas reglamentarias.

c) Sostienen que el árbitro noruego fue "ineficaz" y que se mostró opuesto a ellos y favorable al Perú.

El asunto es puesto en manos del Tribunal de Apelación de la FIFA, presidido por el francés J. Rimet (presidente de la FIFA) y conformado por Italia, Suecia, Bélgica, Checoeslovaquia y otras naciones europeas.

Representan al Perú en estas diligencias el referido señor Martínez, además de Dasso y Mujica Gallo.

La delegación peruana sale al frente de los reclamos austriacos y refiere:

a) Que el acceso de gente al campo no fue una falta del Perú sino responsabilidad de los organizadores y un "tema policial". Además, el reclamo debió presentarse ante el árbitro en el momento que ocurrió el incidente.

b) Sobre al campo de juego, éste había sido designado por los organizadores en varios juegos. Si las medidas no eran las adecuadas ello afectaba a los peruanos habituados a jugar en campos más grandes.

c) Respecto a la actitud del árbitro, ésta fue perjudicial para el Perú pues "anuló 2 'goals' legales".

Se llevó a cabo la deliberación en privado para luego informar el fallo a los representantes de Perú y Austria.
La decisión fue anular el partido, basándose para ello en el ingreso de gente al terreno de juego y agresión al equipo austriaco, por tanto, se resolvió jugar de nuevo dicho encuentro. El partido se haría ese mismo día lunes a las 5 de la tarde en el Post-Stadion sin público y con sólo 3 acompañantes por equipo, más las autoridades y la prensa.

Martínez no acepta y por "órdenes de Lima" prepara el viaje de la delegación peruana a París. Es notoria entonces la negación del Gobierno del Perú a aceptar este fallo.

El profuso informe de H.E. Gildemeister anota también la presencia del Gobierno del Reich en el problema:

"Esa misma tarde del lunes 9 [debería decir lunes 10], el Ministro de Propaganda e Ilustración se comunicó con esta Legación para que el equipo desistiera del viaje que proyectaba y ofreció, que aunque el asunto era de carácter netamente deportivo y el Gobierno alemán no tenía ninguna autoridad sobre la FIFA, trataría de intervenir para conseguir una solución favorable del problema que se había suscitado ${ }^{18 " .}$.

Si el Gobierno alemán no tiene autoridad sobre la FIFA ¿cómo entonces se ofrece a "intervenir"? Es lógico pensar que los alemanes no querían ser mal vistos ante los ojos del mundo, no querían ver empañadas sus Olimpiadas planeadas para mostrar la imagen de la superioridad aria y a una Alemania que renacía luego de la Primera Guerra Mundial, por ello sus supuestos "buenos oficios" ante la FIFA.

El Perú, en protesta por la anulación de su triunfo, no se presentó al nuevo encuentro en la tarde del lunes frente a Austria por lo que éste último equipo fue dado por ganador quedando seleccionado para jugar las semifinales ante Polonia el martes 11.

Alfredo Benavides, miembro del Comité Olímpico Internacional, visita al Secretario General de la FIFA rechazando el fallo de anulación. De igual modo Gildemeister señala la llegada de numerosos telegramas de países sudamericanos sumándose a la protesta peruana. Así, por ejemplo, el Ministro de Colombia, señor Obregón Arjona, se aúna a la defensa de la causa del Perú.

En estos términos el Tribunal de Apelación, a través de J. Rimet, efectúa una nueva propuesta: Perú debería jugar contra Austria el día martes y el ganador enfrentaría a Polonia ese mismo día ¿se debería esta propuesta a una intervención del gobierno nazi? Dejando marcada su insatisfacción por todo lo ocurrido, "Lima rechaza" la propuesta, el acatarla hubiese significado la aceptación del fallo inicial que

18 Ibídem. 
anuló el primer partido. Por otro lado el equipo austriaco, que sigue en la lid, vence a Polonia. Se inicia un movimiento de parte de las misiones diplomáticas. El día miércoles los representantes diplomáticos sudamericanos se reúnen en la Embajada de Brasil con el fin de solicitarle a la FIFA la anulación del fallo que perjudicó al Perú, por ello piden que nuestra delegación permanezca en Berlín hasta el término de esta gestión. Debido a que el viaje ya no se puede postergar, la delegación peruana se dirige a Colonia no saliendo de Alemania en espera de un resultado. Al volver a ser éste negativo los peruanos finalmente viajan a París el viernes 14.

En 2 ocasiones Gildemeister fue llamado por el Ministro de Relaciones Exteriores alemán quien le manifestó su "extrañeza" por las manifestaciones peruanas de protesta contra la Legación alemana y las casas comerciales de dicha bandera en Lima. Al Ministro del Reich dichas manifestaciones le parecían un hecho "injusto" pues decía que nada había tenido que ver la autoridad alemana en el problema surgido. Señalaba además que dentro del Jurado de la FIFA, Alemania era sólo un país "observador" y "sin voto". Efectivamente, conocido en el Perú el fallo de anulación, la agitación social no se hizo esperar. Un grupo de manifestantes se agolpó frente al Palacio de Gobierno en Lima para reclamar por lo sucedido. El General Benavides los recibió desde uno de los balcones y les manifestó que se buscaría una solución. No obstante, con los ánimos ya caldeados, los manifestantes se dirigieron a la Legación alemana para arrojarle piedras.

El Ministro de Propaganda nazi, el Presidente del Comité Organizador Olímpico, el Presidente de la Federación Alemana de football y la prensa, buscan poner en claro que en nada hubo intervención del gobierno alemán, sin embargo, Gildemeister acusa que en ningún momento condenaron el fallo de la FIFA contra el Perú.

El Comité Olímpico Internacional lamenta lo ocurrido y manifiesta no poder hacer nada pues la FIFA es autónoma en sus decisiones.

Martínez, por su parte, hace responsable a dicho Comité. El Tribunal de Honor "rechaza responsabilidad" y califica la actitud de la delegación peruana de "antideportiva" y que "demostraba ignorancia culpable de los reglamentos olímpicos".

Hice referencia a la acción conjunta de las misiones diplomáticas sudamericanas a favor del Perú, pero revisando con detenimiento el informe de Gildemeister, éste indica el rápido cambio de postura de los países sudamericanos:

"Por último no quiero dejar de poner en conocimiento de Ud. que antes de la clausura del Congreso de la FIFA reunido en esta capital, Colombia ha ingresado al seno de ella y el representante uruguayo señor Dupuy, quien había hecho una valiente defensa de la causa peruana, terminó solicitando una medalla de oro para el presidente de la FIFA señor Rimet ${ }^{19 \prime}$.

Un antecedente más de la debilidad para forjar una verdadera integración que emerja por iniciativa propia de nuestros países latinoamericanos.

Si en un tema tan simple como la reclamación deportiva peruana no pudo haber una duradera voluntad de apoyo ¿qué se podría esperar en temas mucho más intrincados?

Gildemeister también envía, en su informe al Ministerio de Relaciones Exteriores en Lima, extractos de artículos concernientes al "incidente peruano" publicados en la prensa inglesa.

Dicha prensa acusa una "falta de espíritu olímpico" por parte del Perú debido a las manifestaciones frente al Palacio Presidencial en Lima y apedreamiento a la Legación alemana, además la prensa inglesa añade:

"Presumimos que el incidente pasará rápidamente, el Océano Atlántico y la Doctrina Monroe son suficientes garantías de seguridad ${ }^{20 \prime \prime}$

De esto se deduce que los ingleses estaban seguros que la lejanía y la "América para los americanos" sostenida por la doctrina Monroe, impedirían proseguir con cualquier tipo de reclamación por este incidente. Mejor dicho que EEUU se encargue de controlar los problemas de los países bajo su órbita de influencia y así estas naciones no lleguen a ser fastidio a los europeos. Se reporta también sobre el "boycot contra tiendas alemanas", el hecho que los estibadores del Callao no querían trabajar en barcos de bandera alemana, la bandera olímpica había sido destruida, se habría amenazado con un revólver a un referee alemán, los estudiantes peruanos de colegios y universidades se habían declarado "en huelga". Todo ello fue publicado en la prensa inglesa.

Tampoco dudan en señalar, usando para ello una analogía, la cercanía del fascismo con el General Benavides:

"La Federación Internacional de Football ordenó se vuelva a jugar el partido, casi lo mismo que cuando la Liga de las Naciones ordenó a Mussolini se batiera nuevamente después de haber vencido a Abisinia. El General Benavides, el Mussolini del Perú, ordena se 
retire la delegación peruana, al igual que el Barón Aloisi se retiró en Ginebra, y, regresar al país ${ }^{21 "}$.

La FIFA busca darse por ofendida ante los sucesos desencadenados luego del fallo que emitió. El Dr. Shricker, Secretario de la FIFA, habla en estos términos: "esperaba que el verdadero espíritu deportivo prevalecería, pero me he desilusionado amargamente ${ }^{22 \prime \prime}$.

Buscan presentar la idea de que los juegos olímpicos deben continuar, pues quienes no demuestran espíritu deportivo (es decir los peruanos) ya están fuera del torneo. Poco tolerables son las expresiones de la prensa inglesa que van contra la imagen de los países latinoamericanos:

"En aquellos lejanos climas, los espectadores creen tener derecho a ser combatientes como los jugadores que están sedientos de la sangre de los rivales, y se emplea, cuchillos, fusiles y garrotes como argumento de discusión. Pero los austriacos no están todavía habituados a la idea de considerar el football como un deporte de sangre. Aquellos equipos austriacos que hemos visto en este país han complacido a todos por su alta técnica y sus tácticas limpias y escrupulosas. Sus admiradores ingleses pueden darse cuenta de su horror ante lo que para los peruanos no representaban sino frases corrientes de la destrucción de una tarde ${ }^{23 \prime \prime}$.

Lo que esta prensa trata de hacer es una cerrada defensa de los europeos, mostrándolos como ideal de civilización, para ello no dudan en caer en el sensacionalismo hablando de "el verdadero football peruano" en estos términos:

"A pesar de un lamentable incidente en los Juegos Olímpicos, todavía no se ha visto ahí la calidad del juego Latino - Americano en el cual tiene fama de ser la regla cardinal 'si no puedes patear a tu hombre, patea la pelota', aunque el uso de cuchillos está prohibido, excepto para los espectadores durante el primer tiempo. Un partido de football que no va acompañado de incidentes internacionales, venganzas provinciales y el cual el grito de 'Muera el referee!' no es señal de que todos están pasando un buen rato - tal partido, según lo vé un sudamericano, no vale la pena de jugarse ${ }^{24 \prime}$.

Lamentablemente, no se encuentra evidencia inmediata de quejas por parte de los gobiernos latinoamericanos sobre tales manifestaciones.

Finalmente, como nota curiosa cabe anotar que para 1937 la Legación pide se cancele la deuda que se tiene contraída con Gildemeister (quien a la fecha ya no era Ministro Plenipotenciario del Perú ante el Reich) producto de los gastos que se tuvo cuando la delegación de football peruana permaneció en Colonia a sugerencia de los diplomáticos sudamericanos mientras "negociaban" una solución al problema, la misma que nunca llegó. Gildemeister fue quien prestó el dinero para cubrir dichos gastos ${ }^{25}$.

\section{AMISTAD Y COLABORACIÓN PERUANO - ALEMANA}

No todo en las relaciones con Alemania eran quejas e incidentes, así mayoritariamente en el período estudiado se observan signos de colaboración sobre todo académica.

La primera vez que se llegó hasta la cima del Huascarán fue el 20 de julio de 1932. Dicha expedición fue dirigida por el explorador y alpinista alemán Dr. Philipp Borcher, el grupo salió de Bremen el 31 de marzo de 1932 y estaba integrado por 9 personas entre alemanes $y$ austriacos.

Nuestra Legación comunica el envío de 2 ejemplares de Die Weisse Cordillere (La Cordillera Blanca), obra producto del estudio exitoso de los expedicionarios, uno para el Presidente de la República y el otro para el Ministro de Relaciones Exteriores.

Se informa que se esta planificando una nueva expedición dirigida a la zona norte de la Cordillera Blanca a cargo del geógrafo austriaco Hans Kinzl de la Universidad de Innsbruck, esta vez no se tiene presencia de alemanes pues éstos no lograron contar con los recursos necesarios para la expedición ${ }^{26}$.

También es tiempo de reconocimientos a intelectuales. El gobierno peruano otorga la condecoración "El Sol del Perú" al profesor Max Uhle por su "destacada labor arqueológica en el Perú"27.

El apoyo en temas académicos está presente. La Legación peruana avisa a Lima que el Ministro de Educación de Sajonia ha otorgado ya el permiso al profesor Bruno Moll, de Leipzig, para que pase al Perú por 3 años ${ }^{28}$ (recordado por obras en temas financieros como La moneda y Finanzas y Guerra). Ello no es una característica sólo de este período. Tiempo atrás ya había llegado el estudioso de la botánica peruana, Augusto Weberbauer (1901).

También se pone en conocimiento que la empresa cinematográfica "Tobis", por intermedio de los

\footnotetext{
25 Oficio del 25 de octubre de 1937.

26 Oficio del 2 de marzo de 1936.

27 Oficio del 6 de marzo de 1936.

28 Oficio del 7 de mayo de 1936.
} 
señores Ribeiro y Von Szczepanski, estaba interesada en preparar películas culturales sobre nuestro país ${ }^{29}$. La colaboración no es sólo en temas intelectuales sino también en misiones de estudio concernientes a asuntos militares:

"La legación del Perú saluda atentamente al Ministerio de Negocios Extranjeros Alemán y tiene el honor de informarle que su Gobierno ha comisionado al Comandante A. Balaguer, Agregado Naval a esta Legación, para que estudie todo lo concerniente a la organización y mantenimiento, tanto industrial como militar, de Diques y Arsenales de la Armada Alemana ${ }^{30 \prime}$.

Al respecto la Legación solicita se le brinden a Balaguer todas las facilidades del caso en esta labor de estudio.

Para el año 1938 aún se veían signos de buenas relaciones, así tenemos por ejemplo la preparación del programa "Ibero - América en el Reich" que sería emitido en el mes de febrero por "La Emisora Alemana de Ondas Cortas de Berlín" cuya señal llegaba hasta el Asia, África y América. Su finalidad era mostrar "el intercambio cultural e intelectual entre los países ibero - americanos y Alemania ${ }^{31 " .}$.

\section{OTRAS INFORMACIONES}

Es interesante anotar en este apartado las comunicaciones sostenidas entre Gildemeister desde Alemania y las autoridades de nuestra Cancillería en Lima con noticias sobre el desarrollo del nacionalsocialismo bajo el título: "Política internacional en relación con la política alemana ${ }^{32 ": ~ " D e s p u e ́ s ~ d e ~ t o d o ~}$ queda aun pendiente la incógnita: ¿Cuánto tiempo se mantendrá económicamente el Reich alemán dentro de la situación de cada día peor de carencia de las divisas necesarias? ¿Y se conseguirá suprimir las fuerzas obstaculizantes en el interior hasta que se haya llegado a una consolidación, cuyo sostén sólo puede ser el ejército? ${ }^{33 \prime}$.

Debido al interés que se tenía sobre la política alemana, ya que el Perú se había venido acercando más a este país, no se hacen esperar nuevos envíos de información, en éstos se señala la preocupación por la agravada radicalidad que van tomando cada día las fuerzas nacionalsocialistas (sobre todo la Gestapo):

"Otro síntoma de la radicalización es el nuevo agrupamiento que se ha hecho con la policía. Toda la policía del país se ha subordinado ahora últimamente a los elementos radicales del partido [nazi], y constituyendo la policía el factor de poder que sigue inmediatamente al ejército en importancia, significa dicha reorganización un nuevo reforzamiento interno de las tendencias extremistas del partido Nacional Socialista ${ }^{34 \prime}$

De igual modo nuestra Legación envía datos sobre recientes actividades desarrolladas por países sudamericanos anunciando que se trata de noticias de "interés" para el Ministerio de Guerra peruano ${ }^{35}$. Argentina pensaba comprar aviones por un valor de 42 millones de pesos.

Chile había enviado a Alemania una delegación de 17 militares que no logran comprar armas pues el precio de la cuota de salitre vendido a Alemania había caído en un $30 \%$. No obstante, al mejorar los términos de intercambio, se había vuelto a enviar un comisionado pero hasta el momento de envío del cablegrama no se tenía noticia de compra alguna de armamento.

Por su parte Colombia suscribía un contrato por alrededor de 1 millón de marcos alemanes para adquisición de camiones y tractores, además negociaba la construcción de carreteras y puentes.

Esta nota puede ser entendida como parte de nuestra constante necesidad de observar a los países vecinos debido a las viejas rencillas ocasionadas por conflictos (sobre todo en el caso de Chile) y por la importancia de estar al tanto del avance militar en la región relacionado al balanceo de relaciones de poder.

\section{Conclusiones}

Los problemas que se presentan durante el período estudiado (1935-1937), tanto el caso Hochkoeppler como el caso Ebentreich, pueden bien ser vistos como incidentes aislados, producto de animadversiones personales por parte de ciertos ciudadanos alemanes seguidores de la doctrina nazi. Estos son los casos conocidos para el referido lapso de tiempo.

De haber existido un hostigamiento dirigido expresamente desde el Gobierno del Reich, este no habría sido masivo (para el período estudiado se han encontrado tan sólo 2 casos de los que se tienen noticias oficiales) pues no convenía para el resurgimiento alemán ser mal vistos por el resto del mundo. Mejor dicho, inicialmente, convenía "guardar las formas" necesarias, por lo menos hasta el agravamiento de la situación de guerra.

\footnotetext{
33 Ibídem.

34 Oficio del 19 de junio de 1936.

35 Oficio del 11 de junio de 1937.
}

\footnotetext{
29 Oficio del 16 de febrero de 1937.

30 Oficio del 6 de setiembre de 1937.

31 Oficio del 19 de enero de 1938.

32 Oficio del 19 de mayo de 1936.
} 
Sobre el incidente de las Olimpiadas sí se puede pensar en una injerencia de los nazis, en tanto ésta se evidenciaría en los continuos devaneos de la FIFA. Los nazis pudieron influir en estas decisiones para no ver la eliminación de Austria y que con ello sea mellada su enarbolada imagen de la superioridad aria.

Los signos de colaboración entre Alemania y el Perú se hacen presentes sobre todo en temas académicos. Se vivió un tiempo de acercamiento entre ambos países: "más allá de estos incidentes puntuales provocados durante el régimen nazi, el resto del período se caracterizó por una gran armonía. Esta armonía, el ligero incremento del comercio bilateral y la celebración de algunos importantes acuerdos bilaterales hicieron tener esperanzas de una fructífera relación ${ }^{36 \prime}$

Efectivamente, nuestras relaciones exteriores dejaron de mirar hacia los EEUU, como lo habían hecho en la década del 20: "La fecha que simbólicamente marca dicho giro es el 4 de marzo de 1925, en la cual se produjo el fallo Coolidge y el procès verbal brasileño. Ello disipó las ilusiones de la mayoría de peruanos respecto al poder y las preocupaciones del gobierno norteamericano ${ }^{37 "}$.

Así en la década del 30 luego del fracaso de las grandes esperanzas centradas en EEUU (para una favorable resolución de nuestros litigios limítrofes), sumándose a ello la Gran Depresión; la política exterior peruana apuntará hacia Europa, específicamente hacia Italia y las naciones fascistas bajo el influjo de la presidencia del General Benavides:

“En 1933, Sánchez Cerro fue asesinado por un miembro del APRA y, como su sucesor, el Congreso peruano nombró al general Oscar Benavides, comandante en jefe de las Fuerzas Armadas. Benavides había ocupado varios cargos militares y diplomáticos en Europa y mantenía buenas relaciones especialmente con Italia, su gobierno tuvo una actitud fría hacia EEUU, a pesar de que en 1933 Franklin D. Rooselvelt había asumido la presidencia de ese país y había lanzado la política del 'Nuevo Trato' para su país y la del 'Buen Vecino' para América Latina. El comercio entre la mayoría de países latinoamericanos y EEUU y Gran Bretaña iba en aumento de manera considerable entre 1930 y 1940; sin embargo, en el Perú no ocurría lo mismo. Incluso varios años después del fin del gobierno de Benavides, el total

del capital estadounidense en el Perú era solo la mitad de lo que había sido en $1929^{38 "}$.

El ya haberse cerrado asuntos limítrofes con los países vecinos (Colombia y Chile) permitió a Benavides dirigir la política exterior hacia ultramar, optando preferentemente por naciones con las que se sentía identificado, es decir, las fascistas ${ }^{39}$.

Fue así como nos acercamos a la Alemania nazi incrementando el comercio de nuestras exportaciones, entre otros aspectos.

Pese a los incidentes mostrados, el período estudiado es un tiempo de buenas relaciones, aunque no plenamente consolidadas pues no se llegó a elevar nuestra Legación diplomática a la categoría de Embajada. Las relaciones diplomáticas terminan rompiéndose con nuestra posterior inclinación hacia las fuerzas aliadas durante la Segunda Guerra Mundial.

Por lo menos en el plano discursivo, durante el período estudiado, no éramos aún catalogados como "infrahumanidad", la untermenschen del genocidio nazi. Ejemplo de este período de cercanía formal son los discursos durante la presentación de credenciales de nuestro Ministro Plenipotenciario, Manuel Ugarteche, ante el Reich:

"Permitidme, Señor Canciller, que os exprese en nombre de mi Gobierno, en el del pueblo peruano y en mío propio, los votos más sinceros por la creciente prosperidad de vuestro noble país y por la felicidad personal de Vuestra Excelencia ${ }^{40 \prime}$.

Ante ello el Führer Adolf Hitler responde en tono condescendiente:

"Puede Ud. tener la seguridad de que en sus esfuerzos de estrechar más aún las relaciones amistosas y llenas de confianza entre la Alemania y el Perú, y de aumentar el intercambio económico entre nuestros Estados, encontrará usted el absoluto apoyo de parte mía y del Gobierno del Reich"41.

\footnotetext{
${ }^{36}$ Novak, Fabián. Las relaciones entre el Perú y Alemania (1828 2003). Lima: Fondo Editorial de la Pontificia Universidad Católica del Perú, 2004, p.115.

37 Bruce St. John, Ronald. La política exterior del Perú. Lima: Asociación de Funcionarios del Servicio Diplomático del Perú, 1999, p.239.
}

\footnotetext{
${ }^{38}$ McClintock y F. Vallas. La democracia negociada: las relaciones Perú - Estados Unidos (1980-2000). Lima: IEP, 2005, p.48.

39 Novak, Fabián. Las relaciones entre el Perú y Alemania (1828 2003). Lima: Fondo Editorial de la Pontificia Universidad Católica del Perú, 2004, p.108.

40 Oficio del 2 de julio de 1937.

${ }^{41}$ Ibídem.
} 